\title{
Effect of inter-cluster interference on fracture morphology in multi-cluster staged fracturing for shale reservoir
}

\author{
Qing-Chao Li, Yuan-Fang Cheng*, Dong-Xian Zhou, Qiang Li, Ubedullah Ansari \\ School of Petroleum Engineering, China University of Petroleum (East China), Qingdao, Shandong 266580, China. \\ B16020053@s.upc.edu.cn,yfcheng@upc.edu.cn
}

ABSTRACT. Multi-cluster staged fracturing technology is an effective measure to stimulate the reservoir properties. However, the inter-cluster interference effect is obvious when the cluster spacing is very narrow, which seriously affects the effect of fracturing. In order to understand the interference among fracturing clusters within the single fracturing section of the shale horizontal wells during multi-cluster staged fracturing, a finite element model is developed by using ABAQUS finite element simulation software. On this basis, the influences of factors on the fracture morphology are studied. The simulation results have shown that the cluster spacing is the most important factor affecting inter-cluster interference. With the increase in the distance between adjacent clusters, the interference among the fracturing fractures decreases and the propagation of different fractures become homogeneous or similar. Moreover, the increase in the elastic modulus of the shale formation promotes the propagation of the fractures longitudinally, but it hinders the crack opening of the fracture laterally. In addition, properly increasing the injection rate of fracturing fluid during fracturing is more advantageous for obtaining long and wide fractures. Besides, the effect of the fracturing fluid viscosity on fracture width is greater than that on the fracture half-length. The simulation results show the existence of inter-cluster interference comprehensively, which can provide a reference for the design and optimization of multi-cluster staged fracturing to some extent.

KEYWORDS. Multi-cluster staged fracturing; Inter-cluster interference; Shale gas reservoir; Finite element method.

\section{OPEN $\bigcirc$ ACCESS}

Citation: Li, Q. C., Cheng, Y. F., Zhou, D. X., Li, Q., Ansari, U., Effect of inter-cluster interference on the fracture morphology in multi-cluster staged fracturing for shale reservoir, Frattura ed Integrità Strutturale, 44 (2018) 35-48.

Received: 02.12 .2017

Accepted: 28.01 .2018

Published: 01.04.2018

Copyright: (C) 2018 This is an open access article under the terms of the CC-BY 4.0, which permits unrestricted use, distribution, and reproduction in any medium, provided the original author and source are credited.

\section{INTRODUCTION}

$\mathrm{H}$ ydraulic fracturing technology is mainly used for stimulating reservoir properties, and thus promoting the production of oil and gas resources, especially unconventional oil and gas resources such as tight gas and shale gas. Over the past few decades, hydraulic fracturing technology has made considerable progress and has been 
widely used in the development of unconventional resources [1,2], in spite of the fact that its potential environmental impact is gradually attracting attention [3]. With the rapid growth in global energy demand, unconventional oil and gas resources that exist in reservoirs with low permeability, such as shale gas and tight gas, have been under unprecedented exploration and development. The efficient development of unconventional oil and gas resources in the future depends on such factors as resources, technologies and markets [4]. Both the practical production and the numerical simulations have shown that the combination of horizontal well drilling technology and hydraulic fracturing technology will greatly improve the production of unconventional oil and gas resources [5-10]. In the early 1990s, hydraulic fracturing technology began to be used in the development of natural gas in the Barnett Shale, Texas, United States. According to U.S. Energy Information Administration (EIA) statistics, $85 \%$ of the production wells in the United States are currently being developed with horizontal well fracturing technology, and the stimulation effect is significant [11]. In addition, the statistical results also show that the crude oil production from fractured wells accounts for more than $1 / 2$ of the total crude oil production, and the gas produced by fracturing wells even reaches more than $2 / 3$ [12]. Although relevant studies have shown that increasing the design density of perforation is an effective way to improve the productivity of shale gas, an increase in the number of hydraulic fractures will affect the productivity increase of a single fracture. Therefore, the number of fractures within the single fracturing section should not increase infinitely during the multi-cluster staged fracturing operation, and the determination of the cluster spacing becomes the challenge of fracturing design [13].

Until now, some scholars have conducted thorough studies on the mechanical description of the multi-cluster staged fracturing process in shale horizontal wells, which mainly focus on two aspects: initiation and propagation of cracks and reorientation of fractures. Fig.1 shows the initiation and propagation of hydraulically induced fracture during hydraulic fracturing. Zhang Guangming et al. analyzed the factors affecting the fracture propagation of hydraulic fracturing using the three-dimensional fluid-solid coupling model. It was found that factors such as in-situ stress, initial pore pressure and fluid leakage coefficient all have an impact on the fracture propagation in hydraulic fracturing [14]. Pan et al analyzed factors affecting both the location and the pressure of crack initiation. Simulation results show that the increase in both the density and the length of perforation made the initiation pressure decreased, and the presence of both the natural fractures and the cross bedding also affected the initiation of cracks in shale reservoirs [15]. Lo et al. conducted numerical simulations on crack initiation and propagation of brittle rocks during hydraulic fracturing, the simulation results showed that the interaction between fractures aggravated as the fracture propagated [16]. Peirce studied the interference between fractures when the number of clusters in the single fracturing section was different, and the results verified the existence of stress shadowing between fractures. However, the factors influencing the size of stress shadowing and the corresponding influence laws have not been discussed in depth [17]. Although these studies are important for understanding the mechanism of fracture propagation in hydraulic fracturing, they have not been able to do further research on the interaction between hydraulically induced fractures within the single fracturing section in the multi-cluster staged fracturing of shale horizontal wells. In a sense, the effect of inter-cluster interference on fracturing results is more troublesome than that of reservoir heterogeneity [17].

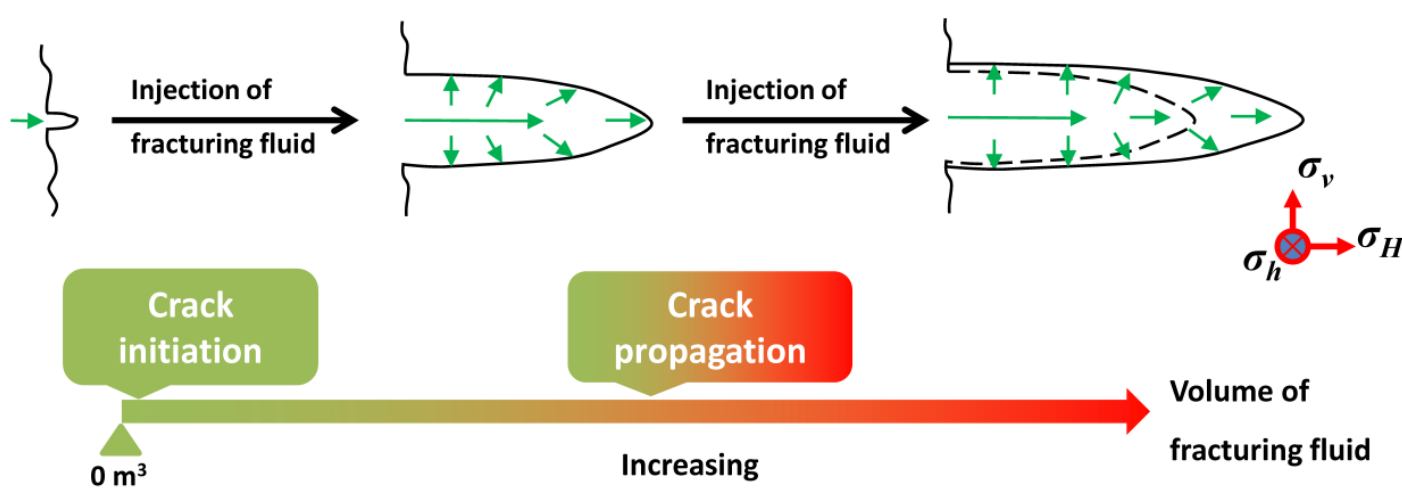

Figure 1: Schematic diagram for the initiation and propagation of hydraulically induced fracture during hydraulic fracturing operation.

In this work, a two-dimensional seepage-stress-damage coupled finite element model is developed based on the cohesive element inside ABAQUS finite element analysis software. Furthermore, the influences of such factors as cluster spacing, formation elastic modulus and injection rate of fracturing fluid on fracture morphology are studied, which can provide a reference for the optimization of the cluster spacing when the multi-cluster staged fracturing operation is performed. In 
the end, optimization is performed for hydraulic fracturing in a shale gas horizontal well in the southwest oil and gas field in China.

\section{FLUID-SOLID COUPLING THEORY FOR HYDRAULIC FRACTURING}

A s shown in Fig.1, there is no crack in reservoir formation at the beginning of the hydraulic fracturing operation. However, with the increase in volume of injected fracturing fluid, cracks appear firstly in the direction of the 1 maximum horizontal principal stress. Moreover, with the continuous injection of fracturing fluid, cracks will be further propagated and widened. Understandably, hydraulic fracturing is a complicated process involving seepage, rock deformation and damage. In order to analyze the interaction between hydraulically induced fractures, it is necessary to study the fluid-solid coupling theory in hydraulic fracturing process.

\section{Fundamental equations of fluid-solid model}

Based on the principle of effective stress, the fluid-solid analyses of crack propagation are launched and its expression is

$$
\sigma_{\text {effe }}=\sigma_{\text {tota }}+P_{w}
$$

where, $\sigma_{e f f e}$ is the effective stress, $\mathrm{MPa} ; \sigma_{t o t a}$ is the total stress, $\mathrm{MPa} ; P_{w}$ is the pore pressure, $\mathrm{MPa}$.

For porous media of rock, the equilibrium equation can be expressed as the Eq. (2) [14].

$$
\int_{V}\left(\sigma_{e f f e}-m p_{w}\right) \delta_{\varepsilon} d V=\int_{S} t \cdot \delta_{v} d S+\int_{V} f \cdot \delta_{v} d V
$$

where, $m$ is the unit matrix, $\delta_{\varepsilon}$ is the virtual strain rate matrix, $\mathrm{s}^{-1} ; t$ is the surface traction matrix, $\mathrm{N} / \mathrm{m}^{2} ; \delta_{v}$ is virtual velocity matrix, $\mathrm{m} / \mathrm{s} ; f$ is the body force, $\mathrm{N} / \mathrm{m}^{3} ; d S$ and $d V$ are the area and volume respectively.

The continuity equation of pore fluid in the porous rock can be written as the following equation.

$$
\int_{V} \delta v \frac{1}{J} \frac{d}{d t}\left(J \rho_{w} n_{w}\right) d V+\int_{V} \delta v \frac{\partial}{\partial x}\left(\rho_{w} n_{w} v_{w}\right) d V=0
$$

where, $J$ is the volume change rate of porous media, dimensionless; $n_{w}$ is the ratio of fluid volume to total volume, dimensionless; $\rho_{w}$ is the fluid density, $\mathrm{kg} / \mathrm{m}^{3} ; x$ is the space vector, $\mathrm{m} ; d t$ is the time step in $\mathrm{s} ; v_{w}$ indicates the seepage velocity of pore fluid in $\mathrm{m} / \mathrm{s}$.

During hydraulic fracturing, fluid seepage velocity in porous media can be described by Darcy's law [15].

$$
v_{w}=-\frac{k}{n_{w} g \rho_{w}} \cdot\left(\frac{\partial P_{w}}{\partial x}-\rho_{w} g\right)
$$

where, $\mu$ is the fluid viscosity, $\mathrm{Pa} \cdot \mathrm{s} ; K$ is the reservoir permeability in $\mu \mathrm{m}^{2} ; \partial P_{w}$ is the increment of pore pressure, Pa.

Cohesive element method is the commonly used finite element method (FEM) in hydraulic fracturing simulation. Based on the ABAQUS FEM software, the cohesive element method is used to simulate the simultaneous propagation of multiple hydraulically induced fractures within the single fracturing section during hydraulic fracturing in shale horizontal wells. The constitutive model of the cohesive element satisfies the law of traction-separation [14]. That is, it is assumed that the response of the cohesive element before it is damaged satisfies a linear relationship. However, damage of cohesive element occurs when the tractive force exceeds a critical value. In addition, the traction acting on the cohesive element decreases with increasing separation displacement between the two outer surfaces after the damage occurs.

\section{Linear elastic traction-separation behavior}

Stress-strain characteristics of the cohesive element satisfies a linear elastic relationship before damage occurs. 


$$
\sigma=\left\{\begin{array}{l}
\sigma_{n} \\
\sigma_{s} \\
\sigma_{t}
\end{array}\right\}=K \varepsilon=\left[\begin{array}{lll}
K_{n n} & K_{n s} & K_{n t} \\
K_{n s} & K_{s s} & K_{s t} \\
K_{n t} & K_{s t} & K_{t t}
\end{array}\right]\left\{\begin{array}{l}
\varepsilon_{n} \\
\varepsilon_{s} \\
\varepsilon_{t}
\end{array}\right\}
$$

where, $\sigma^{n}$ is the maximum stress that the element can bear in the normal direction, $\mathrm{Pa} ; \sigma_{s}$ and $\sigma_{t}$ are the maximum stress that the element can bear in the first and the second tangential directions respectively, Pa. Likewise, $\varepsilon_{n}, \varepsilon_{s}$, and $\varepsilon_{t}$ are the strains of the element in the normal, the first and the second tangential directions respectively.

\section{Crack initiation and propagation}

Here, the maximum normal stress criterion is the initiation criterion. In other words, the element starts to damage when the stresses in all directions exceed the critical values it can bear. The initiation criterion can be represented by Eq. (6).

$$
\max \left\{\frac{\left\langle\sigma_{n}\right\rangle}{\sigma_{n c}}, \frac{\sigma_{s}}{\sigma_{s c}}, \frac{\sigma_{t}}{\sigma_{t c}}\right\}=1
$$

where, $\sigma_{n c}$ is the tensile strength, $\mathrm{MPa} ; \sigma_{s c}$ and $\sigma_{t c}$ are the critical shear stresses that the element can bear in the first and the second tangential directions respectively, MPa.

For the criterion of crack propagation, crack propagation criteria in BK (Benzeggagh-Kenane) mixed-mode is one of the most frequently used criteria for studying crack propagation. It is particularly useful and efficient when the critical fracture energy along the first shear direction is equal to that along the second shear direction. The criterion can be expressed as the following equation.

$$
G_{n c}+\left(G_{s c}-G_{n c}\right)\left\{\frac{G_{s}+G_{t}}{G_{n}+G_{s}+G_{t}}\right\}^{\eta}=G^{C}
$$

where, variables of $G_{n}, G_{s}, G_{t}, G_{n}, G_{s c}$ and $G^{C}$ are the energy release rate in the normal direction, the energy release rate in the first tangential direction, the energy release rate in the second tangential direction, the critical energy release rate in the normal direction, the critical energy release rate in the first tangential direction and the critical total energy release rate respectively, $\mathrm{Pa} \cdot \mathrm{m} ; \eta$ is a constant related to the material properties, it is 2.284 in this work.

The total energy release rate is defined as $G_{T}=G_{n}+G_{t}+G_{s}$; the fracture begins to propagate when $G_{T}$ is equal to $G^{C}$.

\section{FINITE ELEMENT ANALYSIS SIMULATION}

\section{Numerical modeling and meshing}

he numerical model established in this paper is mainly based on the following assumptions. Firstly, it is assumed that reservoir is a linear elastic isotropic homogeneous formation. Meanwhile, the horizontal wellbore is distributed along the direction of the minimum horizontal principal stress, and the perforation clusters in the single fracturing section initiate synchronously under the action of hydraulic pressure. Furthermore, both the pressure drop of the fracturing fluid flowing within the horizontal wellbore and the influence of perforation friction are neglected. The problem of interference between fracturing clusters in a single fracturing stage during multi-cluster staged fracturing for shale gas horizontal wells can be simplified as a problem of two-dimensional plane strain. Therefore, as shown in Fig. 2 , taking into account the symmetry of the borehole and formation, a two-dimensional finite element model was established by selecting the formation with the size of $400 \times 400$ meters on one side of the horizontal wellbore. Compared with the three-dimensional model, a two-dimensional model can dramatically reduce the number of elements within the model, which can effectively improve the calculation speed of the simulation process. The whole simulation process is independent of the borehole size, so the size of the borehole is not required to define in the model. Generally, it is appropriate to arrange 2 to 5 fracturing clusters in each fracturing section. In this paper, three perforation clusters are designed in each fracturing section. 


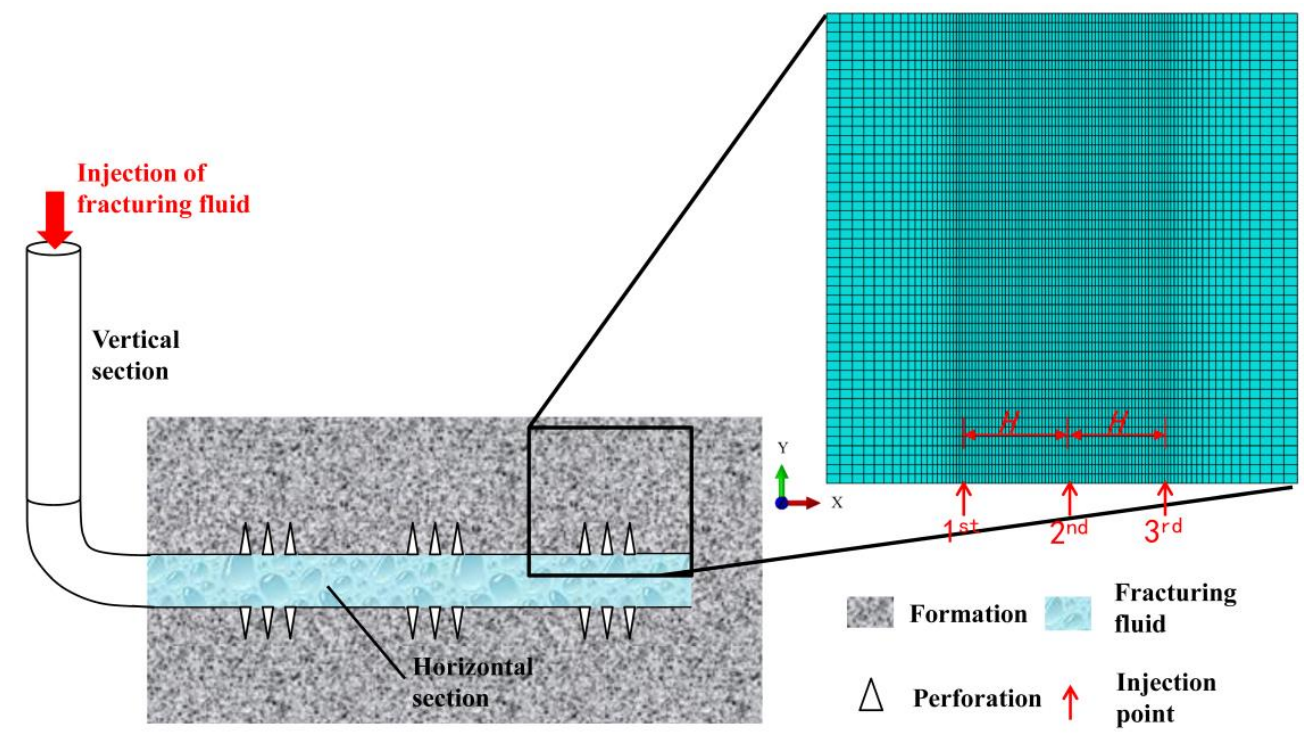

Figure 2: Schematic diagram of multi-cluster staged fracturing for shale gas horizontal well and the established finite element model

Two types of elements, CPE4P and COH2D4P, are used in the model. The CPE4P element can simulate the plane strain problem of porous elastic media, and the whole reservoir is assigned to this type of element. However, both the initiation and the propagation of cracks during hydraulic fracturing operation can be achieved by using COH2D4P element. The whole process of fracture propagation, fluid flow along the fracture and fluid leakage can be simulated by COH2D4P element when the fracturing fluid is injected into the formation. A total of 15,000 CPE4P elements and $800 \mathrm{COH} 2 \mathrm{D} 4 \mathrm{P}$ elements are included in the model.

The model is established by CAE module in ABAQUS software, and on this basis, the secondary development is carried out to realize the numerical simulation of crack propagation. In addition, in order to improve the accuracy of the simulation results and the convergence of the simulation process, the variable density method is used to realize the meshing of the model. That is, the elements near the cracks are more sophisticated and finely divided, which can be seen from Fig. 2.

In terms of boundary conditions and initial conditions, the normal displacement of each boundary is fixed, and the pore pressure boundary is set to be constant along each boundary during the whole simulation process. The initial void ratio, initial stresses and initial pore pressure within the formation are defined by using the predefined field definition in ABAQUS FEM software. In addition, the transient coupling solution has been used for simulating the hydraulic fracturing process.

\section{Material Properties and construction parameters}

According to the mechanical parameters of shale reservoirs and the construction parameters for fracturing operations, factors affecting the interference between different fracturing clusters within the single hydraulic fracturing section are studied. The stratigraphic parameters and construction parameters used in simulation are shown in Tab. 1 and Tab. 2, respectively.

\begin{tabular}{|c|c|c|c|}
\hline Parameter & Value & Parameter & Value \\
\hline Elastic Modulus, E / GPa & 20 & Poisson's ratio, $v$ & 0.2 \\
\hline $\begin{array}{c}\text { Maximum horizontal principal } \\
\text { stress, } \sigma_{H} / \mathrm{MPa}\end{array}$ & 27 & $\begin{array}{c}\text { Minimum horizontal } \\
\text { principal stress }, \sigma_{b} / \mathrm{MPa}\end{array}$ & 16 \\
\hline $\begin{array}{c}\text { Vertical principal stress, } \sigma_{V} / \\
\mathrm{MPa}\end{array}$ & 27 & Saturation, $S_{0} / \%$ & 100 \\
\hline Tensile strength, $C / \mathrm{MPa}$ & 3 & Initial porosity, $\phi / \%$ & 4 \\
\hline Initial pore pressure, $P_{i p} / \mathrm{MPa}$ & 10 & Leakoff coefficient, $l / \mathrm{m} / \mathrm{s}$ & $1 \times 10^{-8}$ \\
\hline Permeability, $K / \mathrm{m}^{2}$ & $5 \times 10^{-17}$ & Length $\times$ Width $/ \mathrm{m}^{2}$ & $400 \times 400$ \\
\hline
\end{tabular}

Table 1: Model parameters of shale gas reservoir. 


\begin{tabular}{cc}
\hline Parameter & Value \\
\hline Viscosity of fracturing fluid, $u / \mathrm{mPa} \cdot \mathrm{s}$ & 1 \\
Injection rate, $Q / \mathrm{m}^{3} / \mathrm{min}$ & 6 \\
Cluster spacing, $H / \mathrm{m}$ & 30 \\
Total fracturing time, $T / \mathrm{min}$ & 10 \\
\hline
\end{tabular}

Table 2: Construction parameters of multi-cluster staged hydraulic fracturing.

The parameters in Tab. 1 and Tab. 2 are only for the standard model, whereas sensitivity studies can be performed by changing the corresponding parameters. On this basis, influences of the factors, such as cluster spacing and the injection rate of fracturing fluid, on the crack morphology are studied by using the FEA model.

\section{SENSITIVITY ANALYSIS}

\section{Effect of cluster spacing on fracture morphology}

$\mathrm{P}$ roper cluster spacing is the key to the design of multi-cluster staged fracturing in horizontal wells. Therefore, in order to study the impact of cluster spacing on the fracture morphology (mainly the crack length and crack width), five different cluster spacings of $10 \mathrm{~m}, 20 \mathrm{~m}, 30 \mathrm{~m}, 40 \mathrm{~m}$ and $50 \mathrm{~m}$ are examined. The width of all fractures studied in this paper is based on the value of the injection point. Fig. 3 shows the contour of fracture morphology after fracturing for 10 minutes when the cluster spacing is different.
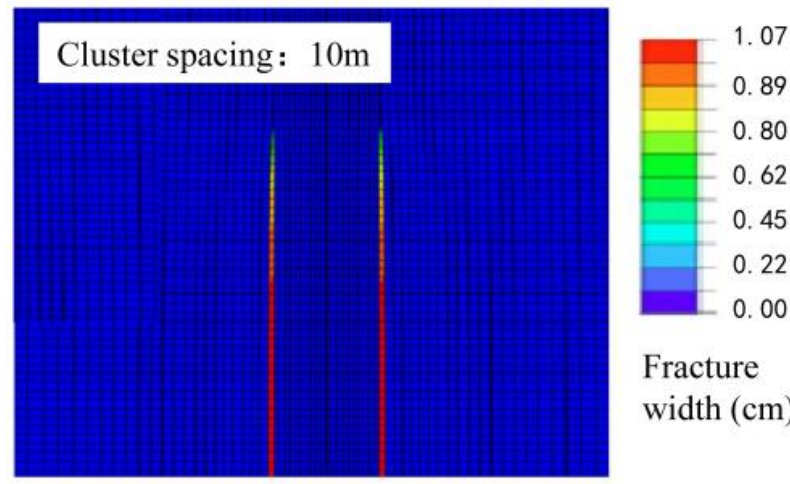

Fracture width $(\mathrm{cm})$

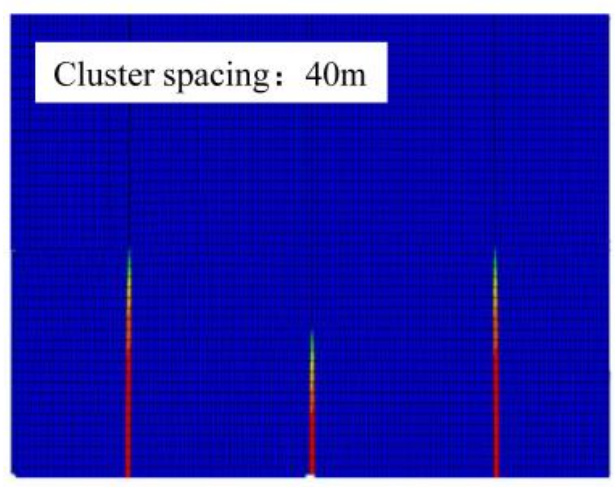

Fracture width $(\mathrm{cm})$

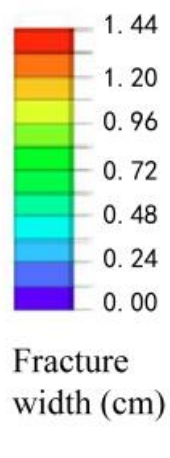

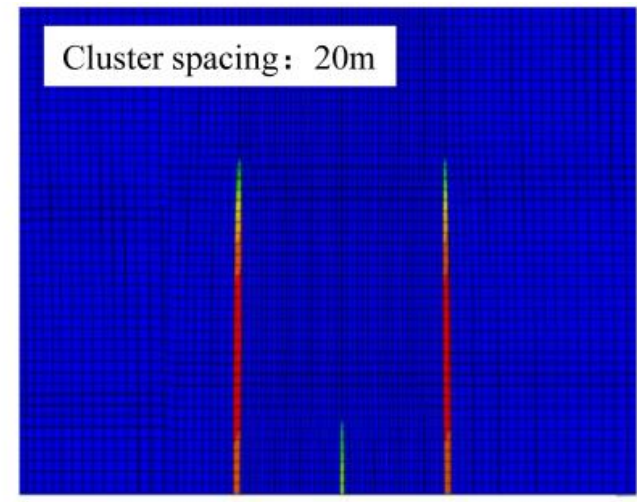

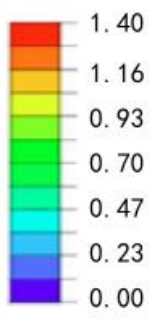

Fracture width $(\mathrm{cm})$
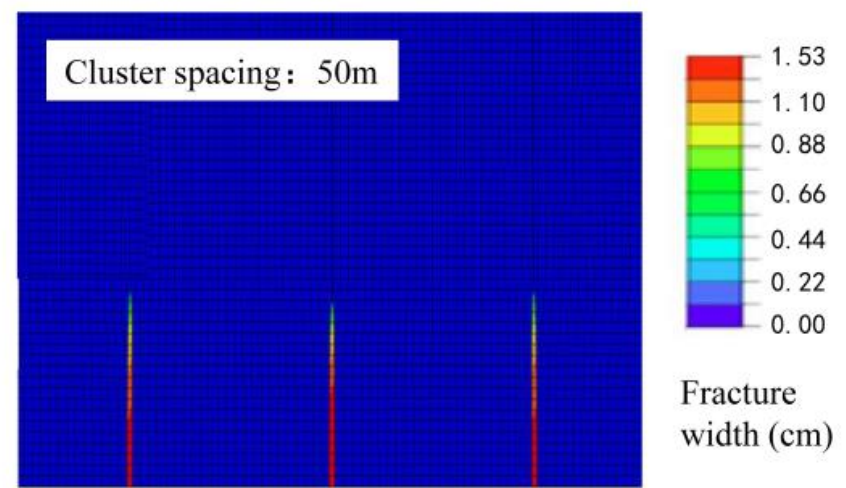

Figure 3: Contour of fracture morphology after fracturing for 10 minutes when the cluster spacing is different. (Deformation scale factor $=500)$.

In order to study the mutual interference of fractures during fracturing, an interference coefficient (In) is defined to characterize this response, which can be expressed by the following equation. 


$$
I n=\left(1-\frac{W_{\text {mid }}}{W_{\text {side }}}\right) \times 100 \%
$$

where, $W$ is the width or the half-length of fracture, and the subscript mid and side represent the middle fracture (the 2 nd fracture) and the two fractures on both sides ( the $1^{\text {st }}$ and the 3 rd fracture). When the coefficient In is less than 1.0 , the existence of interference can be explained. Moreover, the larger the coefficient is, the stronger the interference is. The blue line in Fig. 4 represents the interference coefficient curve.

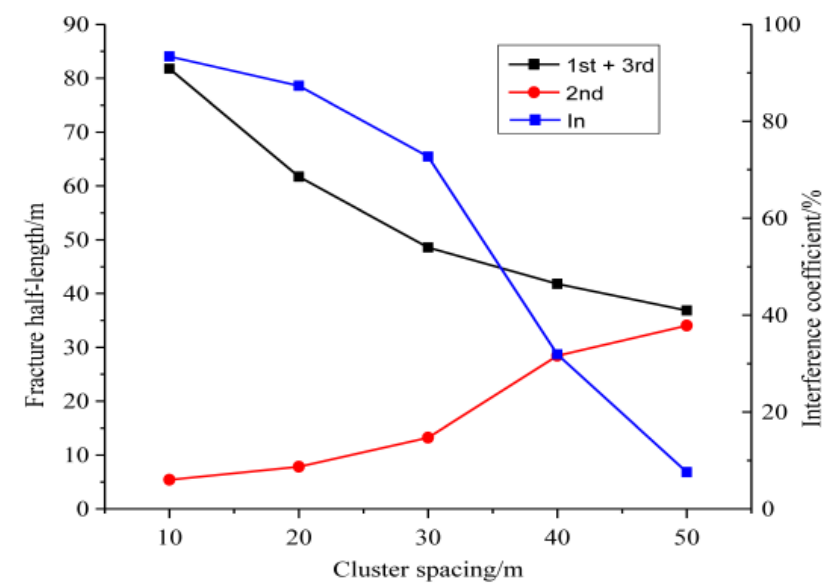

a) Effect of Cluster Spacing on fracture Half- Length

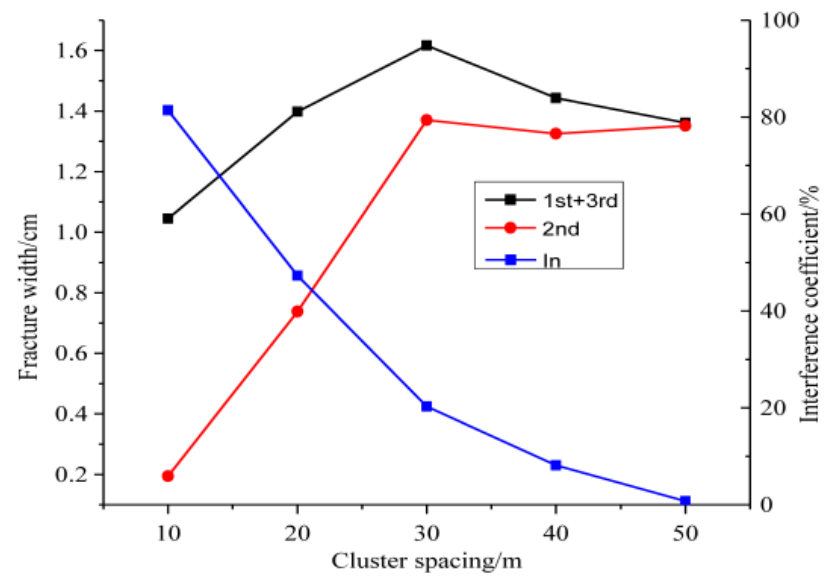

b) Effect of Cluster Spacing on fracture width

Figure 4: Results of fracture propagation when the cluster spacing is different.

Fig.4 shows the results of the fracture half-length (Fig.4a) and the fracture width (Fig.4b) of the three clusters within the single fracturing section when the cluster spacing is different. As can be seen from Fig.3 and Fig.4, the effects of cluster spacing on the morphology of different fractures vary widely, the interference between the fracturing clusters decreases with the increase of the cluster spacing. Under the conditions that the cluster spacing is $10 \mathrm{~m}$, the middle fracture (the $2^{\text {nd }}$ fracture) stops propagating when its half-length is quite small, and the half-length is only $6 \%$ of that of the other two fractures (the $1^{\text {st }}$ fracture and the $3^{\text {rd }}$ fracture), whereas the fracture width is also only $19 \%$ of the width of the other two fractures. This is because that the stress interference between the fracturing clusters is very violent, which strongly inhibits the propagation of the middle fracture. With the gradual increase of the cluster spacing, stress interference between the fracturing clusters gradually diminishes. When the cluster spacing is $30 \mathrm{~m}$, all fractures reach the maximum width, the width of the middle fracture and the other two side fractures are $1.36 \mathrm{~cm}$ and $1.62 \mathrm{~cm}$ respectively. However, when the cluster spacing reaches $50 \mathrm{~m}$, the interference coefficient In reaches nearly zero, which indicates that the interference between fractures almost disappears, and the morphology of all these three fractures are nearly the same.

It can be concluded that the cluster spacing is an important factor affecting the intensity of stress interference among the fractures within the single fracturing section. As the cluster spacing decreases, the stress interference between fractures increases, and the propagation of the middle fracture is seriously suppressed. However, with the increase in the cluster spacing, the stress interference between the clusters decreases or even disappears, and the morphological differences between all fractures become negligible.

\section{Effect of elastic modulus on fracture morphology}

The elastic modulus of reservoir is also another factor affecting both the interference between the clusters and fracture morphology. In this part, the influence of elastic modulus on fracture propagation under the condition of the same cluster spacing is analyzed. Fig.5 illustrates the contour of fracture morphology after fracturing for 10 minutes when elastic modulus is different.

Fig.6 shows the results of the fracture half-length (Fig.6a) and the fracture width (Fig.6b) of the three fracturing clusters within the single fracturing section under different elastic modulus. 

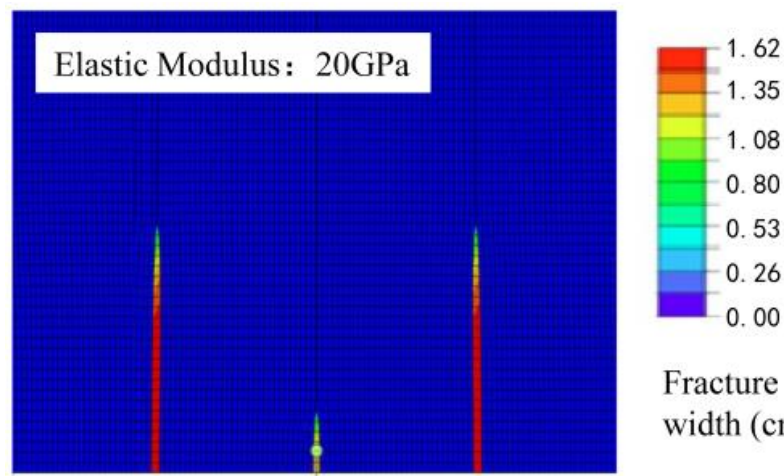

Fracture width $(\mathrm{cm})$
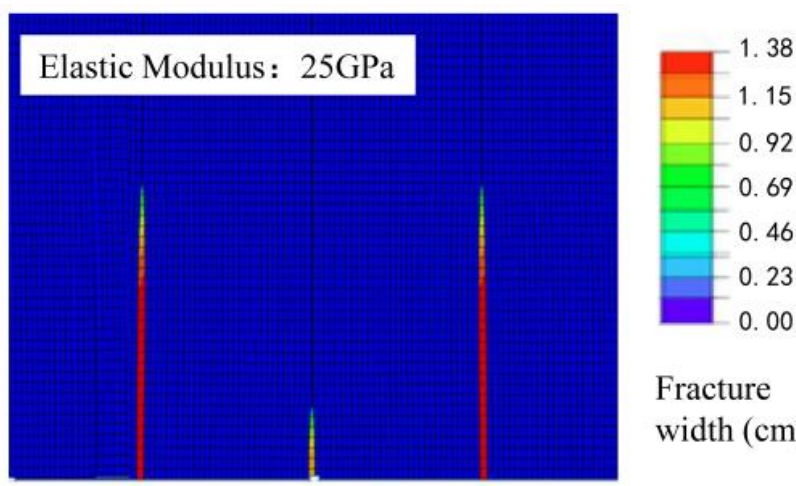

Fracture width $(\mathrm{cm})$
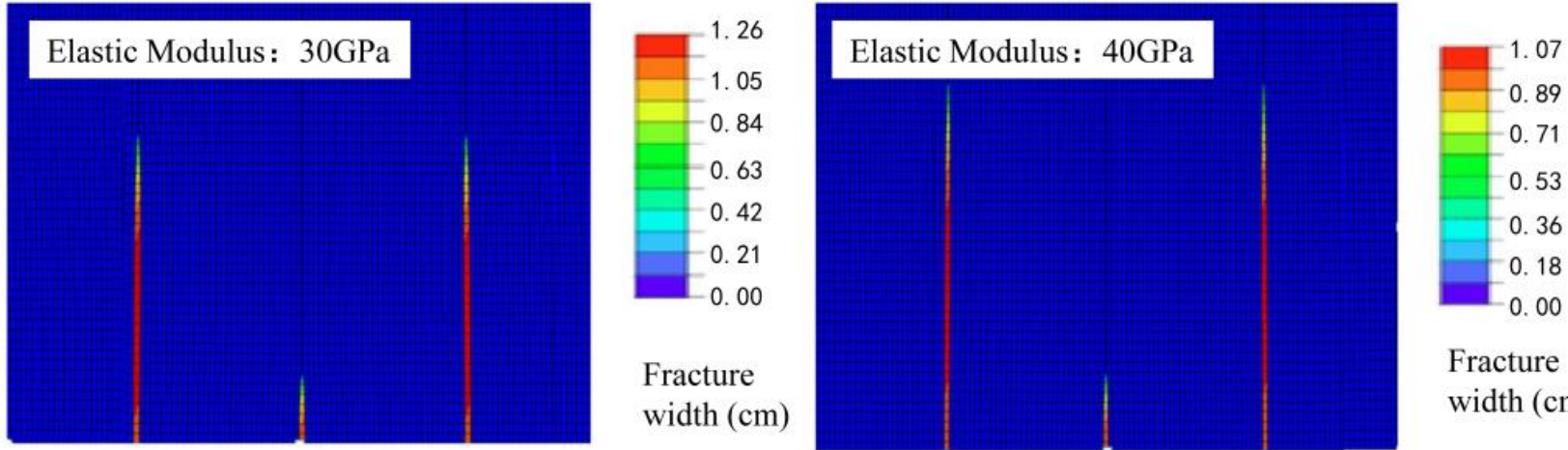

Fracture width $(\mathrm{cm})$
Fracture width $(\mathrm{cm})$

Figure 5: Contour of fracture morphology after fracturing for 10 minutes for formation with different elastic modulus. (Deformation scale factor $=500)$.

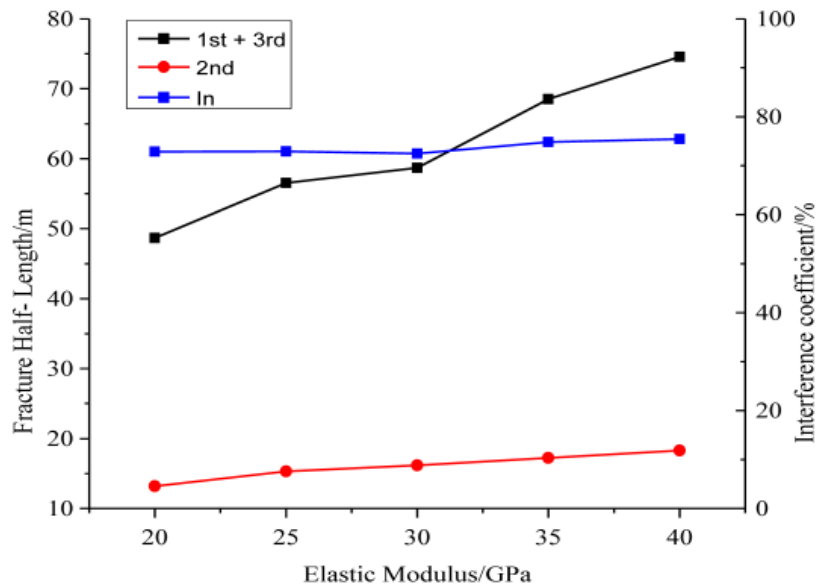

a) Effect of Elastic Modulus on fracture Half- Length

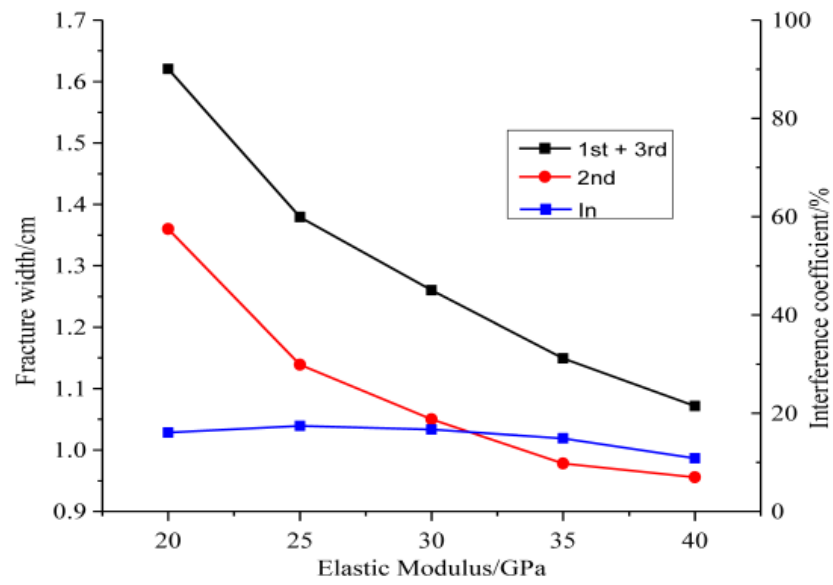

b) Effect of Elastic Modulus on fracture width

Figure 6: Results of fracture morphology for fracture propagation when the elastic modulus of reservoir is different.

As can be illustrated in Fig.6, reservoir elastic modulus can significantly influence fracture propagation, but it hardly affects the interference between fractures, the interference coefficient is almost close to a constant. With the increase of the reservoir elastic modulus, the lengths of all fractures increase, but not significantly. For the $1^{\text {st }}$ fracture and the $3^{\text {rd }}$ fracture, when the elastic modulus increases from $20 \mathrm{GPa}$ to $40 \mathrm{GPa}$, the fracture half-length increases from $49 \mathrm{~m}$ to $75 \mathrm{~m}$, increasing by $53 \%$. Under the same conditions, the half-length of the $2^{\text {nd }}$ fracture also increased from $13 \mathrm{~m}$ to $18 \mathrm{~m}$, which increased by 38\%. Nevertheless, the interference coefficient remains at about $75 \%$. Therefore, it can be concluded that the elastic modulus of the formation does not affect the interference between the fractures in the process of fracture propagation, in spite of the fact that half-length of all fractures increase obviously. 
However, with the increase of the elastic modulus of the reservoir, the width of each fracture decreases significantly, which is opposite to the fracture half-length. The width of both the $1^{\text {st }}$ fracture and the $3^{\text {rd }}$ fracture decreased from $1.62 \mathrm{~cm}$ to $1.07 \mathrm{~cm}$, with a decrease of $34 \%$. However, as for the middle fracture, its width decreased from $1.36 \mathrm{~cm}$ to $0.96 \mathrm{~cm}$, with a drop of $29 \%$. Although varying the elastic modulus of reservoir will change the width of all fractures in the fracturing process, the simulation results of fracture width also show the conclusion that the interference between fractures is hardly influenced by the elastic modulus of reservoirs.

It is an important index to evaluate the success of hydraulic fracturing whether the proppant can enter the fracture smoothly during the fracturing construction. However, increase in the elastic modulus of the reservoir will sharply narrow the width of the hydraulically induced fracture, thereby hindering the proppant carrying and causing sand plug. Therefore, based on the study of the effect of cluster spacing on fracture morphology, for multi-cluster staged fracturing construction in reservoirs with high elastic modulus, large cluster spacing should be designed to avoid the difficulty of sand carrying caused by the smaller crack width.

\section{Effect of injection rate on fracture morphology}

In the case of neglecting the friction of fracturing fluid while flowing in wellbore and assuming that the injection rate at all injection points is the same, the variation of the fracture morphology with the injection rate of the fracturing fluid is studied. Here, five injection rates $\left(5 \mathrm{~m}^{3} / \mathrm{min}, 9 \mathrm{~m}^{3} / \mathrm{min}, 12 \mathrm{~m}^{3} / \mathrm{min}, 15 \mathrm{~m}^{3} / \mathrm{min}\right.$ and $\left.18 \mathrm{~m}^{3} / \mathrm{min}\right)$ are investigated to accomplish the goal. Fig.7 illustrates the contour of fracture morphology after fracturing for 10 minutes under different injection rates of fracturing fluid (when the cluster spacing is $30 \mathrm{~m}$ ).
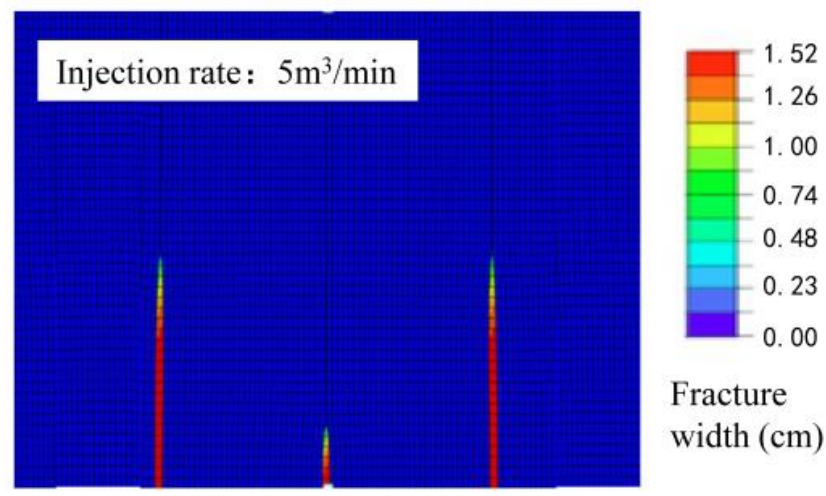

Fracture width $(\mathrm{cm})$
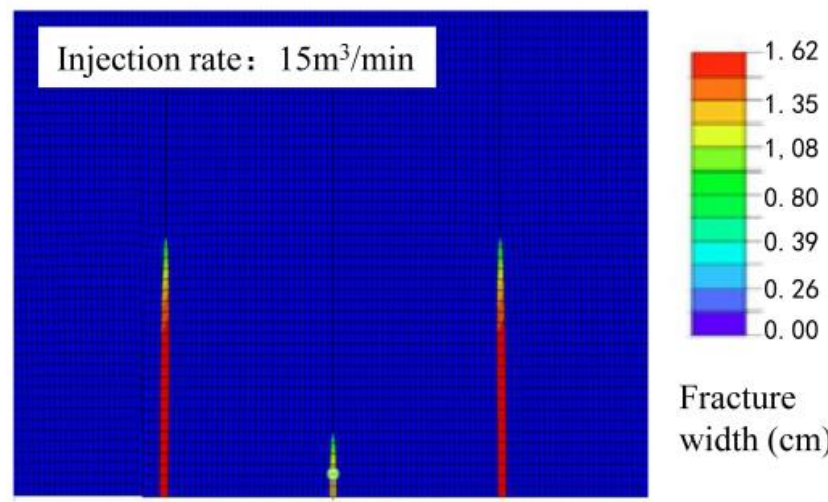

Fracture width $(\mathrm{cm})$
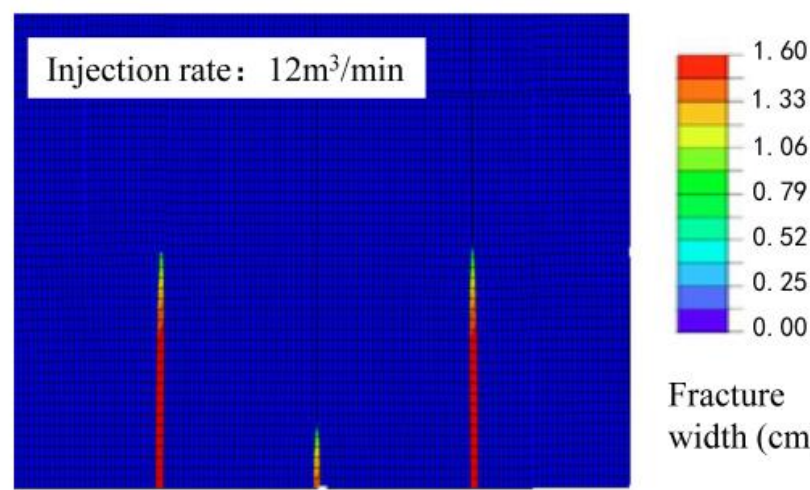

Fracture width $(\mathrm{cm})$

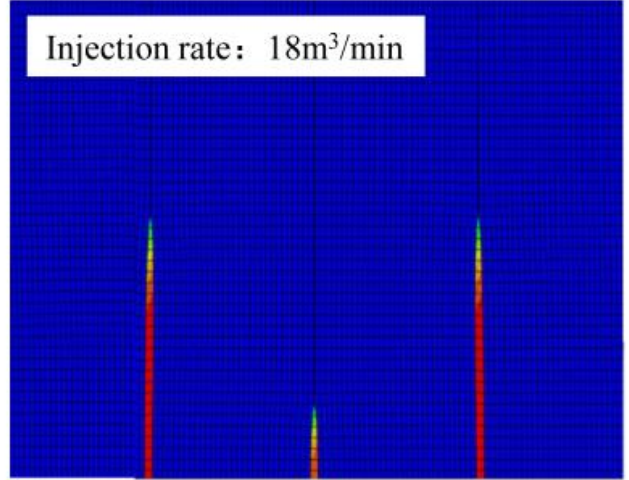

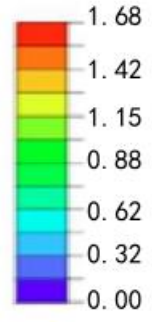

Fracture width $(\mathrm{cm})$

Figure 7: Contour of fracture morphology after fracturing for 10 minutes when the injection rates of fracturing fluid is different. (Deformation scale factor $=500,30 \mathrm{~m}$ cluster spacing).

Fig. 8 shows the results of the fracture half-length (Fig.8a) and the fracture width (Fig.8b) of the three clusters within the single fracturing section when the injection rate is different. As can be seen from Fig.8, with the increase in injection rate of fracturing fluid, both the fracture half-length and the width of all fracturing clusters increase gradually.

As for the fracture half-length, when the injection rate of fracturing fluid increases from 5 to $18 \mathrm{~m}^{3} / \mathrm{min}$, the half-length of two fractures on both sides (the $1^{\text {st }}$ fracture and the $3^{\text {rd }}$ fracture) increases from $45 \mathrm{~m}$ to $51 \mathrm{~m}$, with an increase of $13 \%$. However, although the half-length of the middle fracture (the $2^{\text {nd }}$ fracture) increases only from $11 \mathrm{~m}$ to $14 \mathrm{~m}$, the increase 
range reaches $27 \%$. Similarly, when the injection rate of the fracturing fluid has increased by the same amplitude, the width of the middle fracture (the $2^{\text {nd }}$ fracture) increases from $1.25 \mathrm{~cm}$ to $1.47 \mathrm{~cm}$, with an increase of $17 \%$. However, for two fractures on both sides (the $1^{\text {st }}$ fracture and the $3^{\text {rd }}$ fracture) within the single section, the width increases only from $1.52 \mathrm{~cm}$ to $1.68 \mathrm{~cm}$, by $10 \%$.
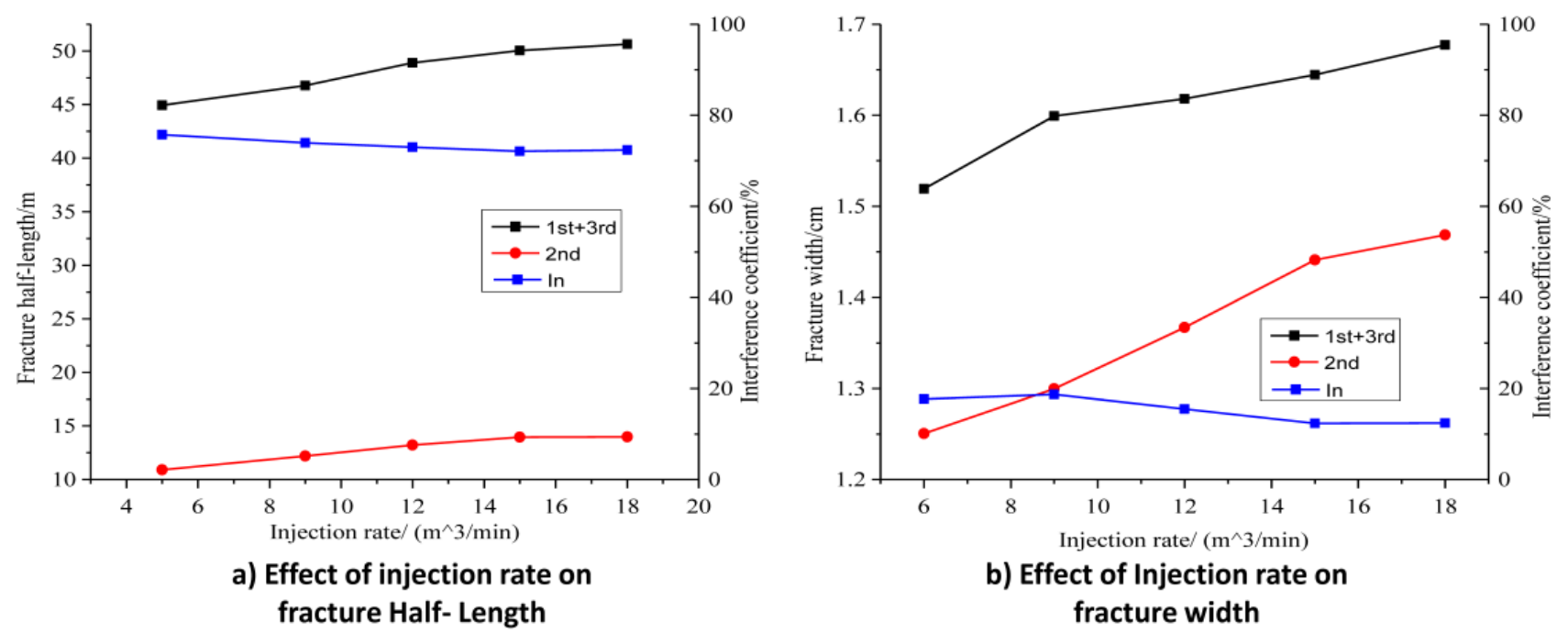

Figure 8: Results of fracture morphology for fracture propagation when the injection rate is different.

However, as can be seen from Fig.8, with the change in the injection rate of fracturing fluid, the interference coefficient during the fracture propagation changes little. When fracture half-length is taken as the criterion to evaluate interference between different fractures, the interference coefficient ranges from $70 \%$ to $80 \%$. However, if the evaluation criterion is converted to fracture width, the interference coefficient ranges from $10 \%$ to $20 \%$. The variation ranges of these interference coefficients are both very narrow. These simulation results indicate that the injection rate of fracturing fluid has only affected the morphology of all the fractures, but hardly influenced the interference between fractures.

By comparison, it can be found that, in terms of the increase amplitude of both the fracture width and the fracture halflength, the middle fracture is always larger than the fractures on both sides. Therefore, when other factors are all optimal, the larger injection rate of fracturing fluid can increase both the fracture width and propagation distance of all fractures within the single fracturing section, thus stimulating the reservoir optimally.

\section{Effect of fracturing fluid viscosity on fracture morphology}

Viscosity of fracturing fluid affects proppant transportation within the fracturing fluid, thereby affecting the stimulation result of the reservoir after fracturing construction. Here, five viscosities $(1 \mathrm{mPa} \cdot \mathrm{s}, 20 \mathrm{mPa} \cdot \mathrm{s}, 50 \mathrm{mPa} \cdot \mathrm{s}, 100 \mathrm{mPa} \cdot \mathrm{s}$ and $200 \mathrm{mPa} \cdot \mathrm{s}$ ) are examined to study the influence of the viscosity of fracturing fluid on fracture propagation. Fig.9 shows the contour of the fracture morphology after fracturing for 10 minutes by using fracturing fluid with different viscosities when the cluster spacing is $30 \mathrm{~m}$.

Fig. 10 shows both the half-length (Fig.10a) and the width (Fig.10b) of all these three fractures by using the fracturing fluid with different viscosities when the cluster spacing is $30 \mathrm{~m}$. As illustrated in Fig.10, the width of each fracturing cluster increases gradually with the increase in fracturing fluid viscosity, but the fracture half-length shows the opposite trend, that is, shows a slight downward trend. In spite of this, different influences of the fracturing fluid viscosity on the morphology of different fractures are evident. When the fracturing fluid viscosity increases from $1 \mathrm{cP}$ to $200 \mathrm{cP}$, the width of two fractures on both sides (the $1^{\text {st }}$ fracture and the $3^{\text {rd }}$ fracture) within the fracturing section increases by $9 \%$ (from $1.62 \mathrm{~cm}$ to $1.76 \mathrm{~cm}$ ), whereas the middle fracture (the $2^{\text {nd }}$ fracture) shows the thinner width (increases from $1.36 \mathrm{~cm}$ to $1.46 \mathrm{~cm}$ ), increasing only by $7 \%$.

Compared with the other three factors (cluster spacing, elastic modulus and injection rate) mentioned above, the impact of the fracturing fluid viscosity is relatively small, which can be seen by the shape of the curves in Fig.10, especially the fracture half-length curve. The increase in viscosity of fracturing fluid shortens all fractures that propagate simultaneously within the single fracturing section, but the effect of viscosity on the half-length of different fractures is different. When the viscosity of fracturing fluid increased from $1 \mathrm{cP}$ to $200 \mathrm{cP}$, the half-length of the middle fracture (the $2^{\text {nd }}$ fracture) shortened by $4 \%$, whereas the two fractures on both sides (the $1^{\text {st }}$ fracture and the $3^{\text {rd }}$ fracture) shortened by $12 \%$. Blue 
lines in both subgraphs within Fig.10 are almost horizontal straight lines, which indicate that the interference between the fractures within the single fracturing section is independent of the fracturing fluid viscosity.
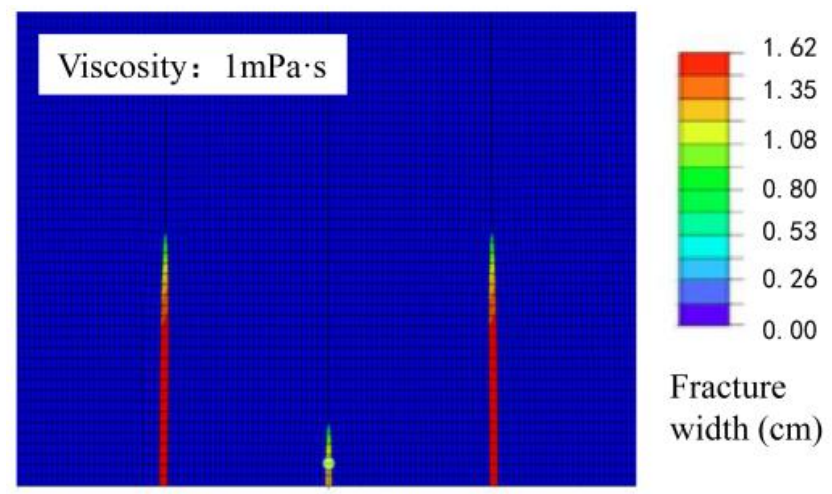

Fracture width $(\mathrm{cm})$
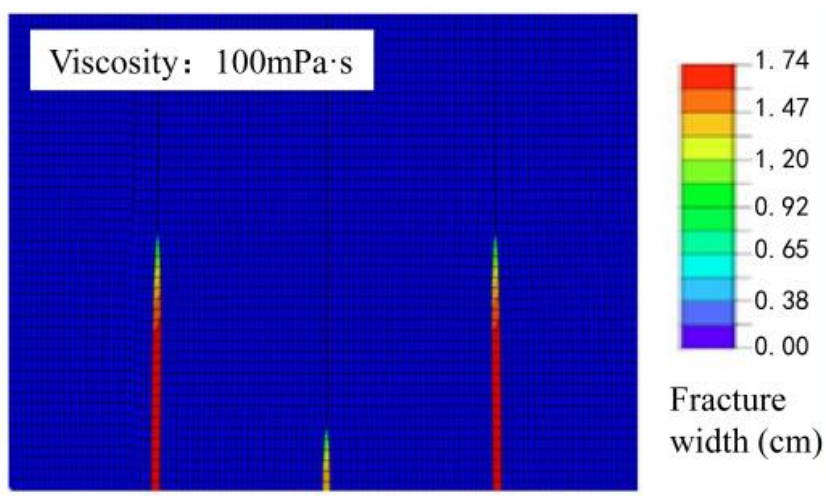

Fracture width $(\mathrm{cm})$
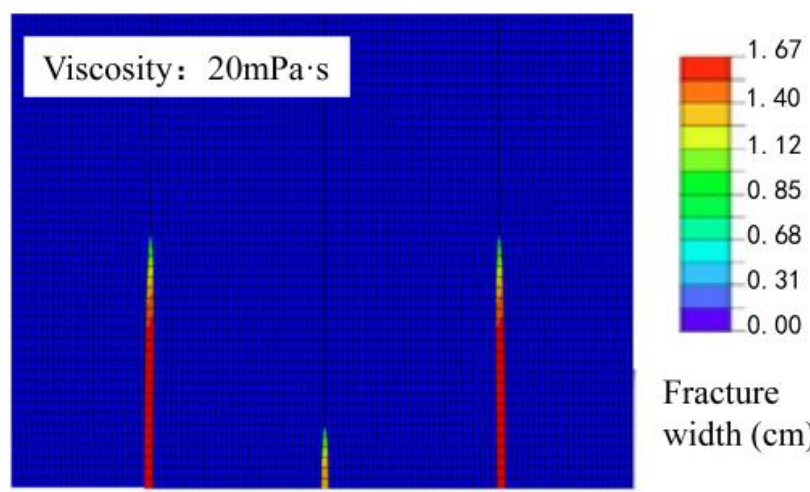

Fracture width $(\mathrm{cm})$

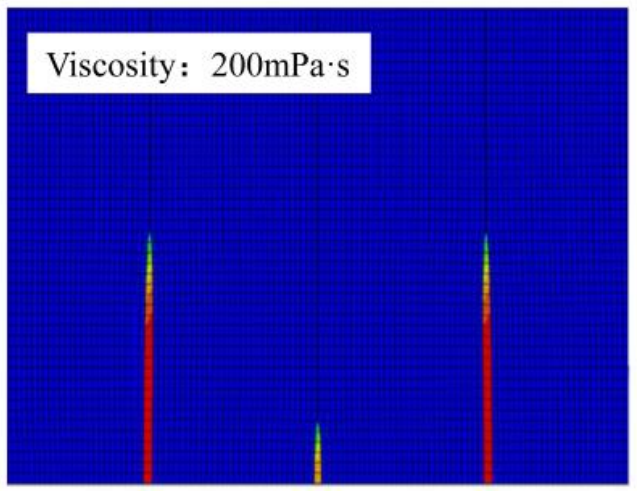

Fracture width $(\mathrm{cm})$

Figure 9: Result of fracture morphology after fracturing for 10 minutes by using fracturing fluid with different viscosities. (Deformation scale factor $=500,30$ cluster spacing).

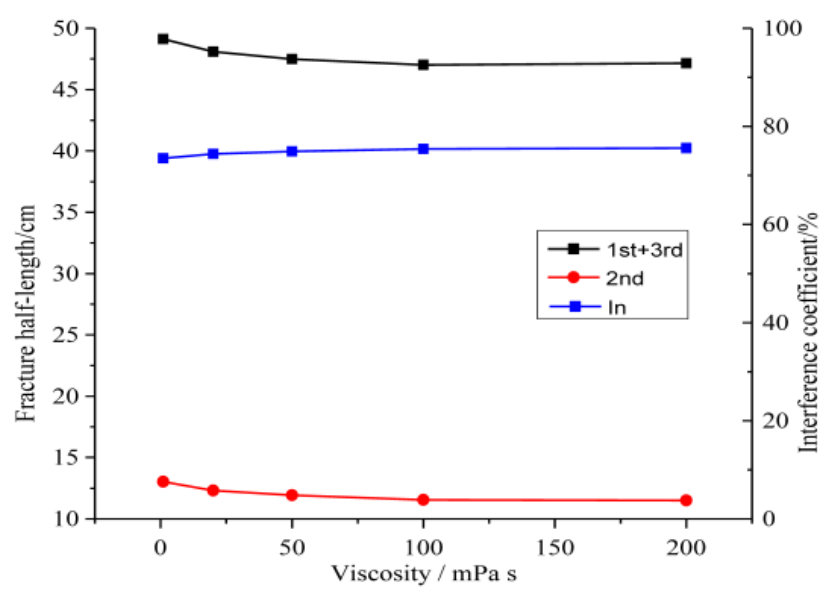

a) Effect of viscosity on fracture Half- Length

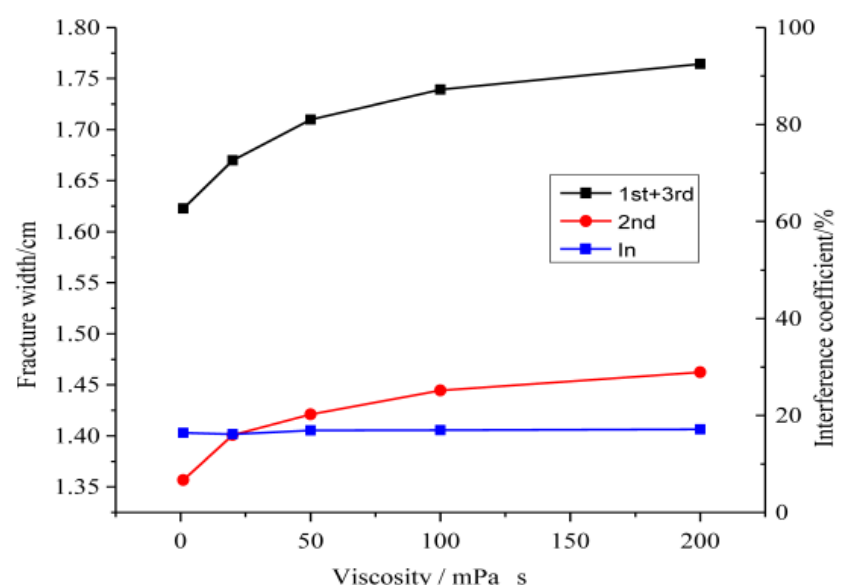

b) Effect of viscosity on fracture width

Figure 10: Results of fracture morphology for fracture propagation when the viscosity of fracturing fluid is different.

The research shows that the short and wide fracture can be obtained by increasing the viscosity of the fracturing fluid. Although the width of the fractures can be increased by this, the length of the fractures may decrease, which is not conducive to increasing the volume of the reservoir stimulated by hydraulic fracturing. 


\section{CASE STUDY}

B

ased on the above studies, it is found that cluster spacing is the most important factor affecting the interference between cracks, while other factors have little impact on it. Consequently, taking a shale gas horizontal well located in the southwest oil and gas field of China as an example, the hydraulic fracturing construction has been optimized and designed.

The lithology of the target reservoir for multi-cluster staged fracturing in the well is mainly the silty and the carbonaceous shale, and the complicated bedding is well developed in shale reservoir. The elastic modulus and Poisson's ratio of reservoir rocks are $20.1 \mathrm{GPa}$ and 0.21 , respectively. For the properties of the reservoir rock matrix, the content of brittle minerals is high with a brittleness index ranging from 0.5 to 0.6. The matrix porosity is very low, ranging from $1.17 \%$ to $7.72 \%$, and matrix permeability varies between $1.0 \times 10^{-18} \mathrm{~m}^{2}$ to $1.2 \times 10^{-16} \mathrm{~m}^{2}$, so the reservoir can be defined as ultra-low permeability formation. The maximum horizontal stress and the minimum horizontal stress of the reservoir are $28.5 \mathrm{MPa}$ and $19.9 \mathrm{MPa}$ respectively, and the total length of the horizontal section is $1215 \mathrm{~m}$. The multi-cluster perforation scheme is used as the completion pattern, with three perforation clusters designed within one fracturing section. The injection rate of fracturing fluid is $14 \mathrm{~m}^{3} / \mathrm{min}$. Based on the model established above, the cluster spacing optimization is performed. Fig.11 shows the fracture half-length of all fractures when the cluster spacing is different.

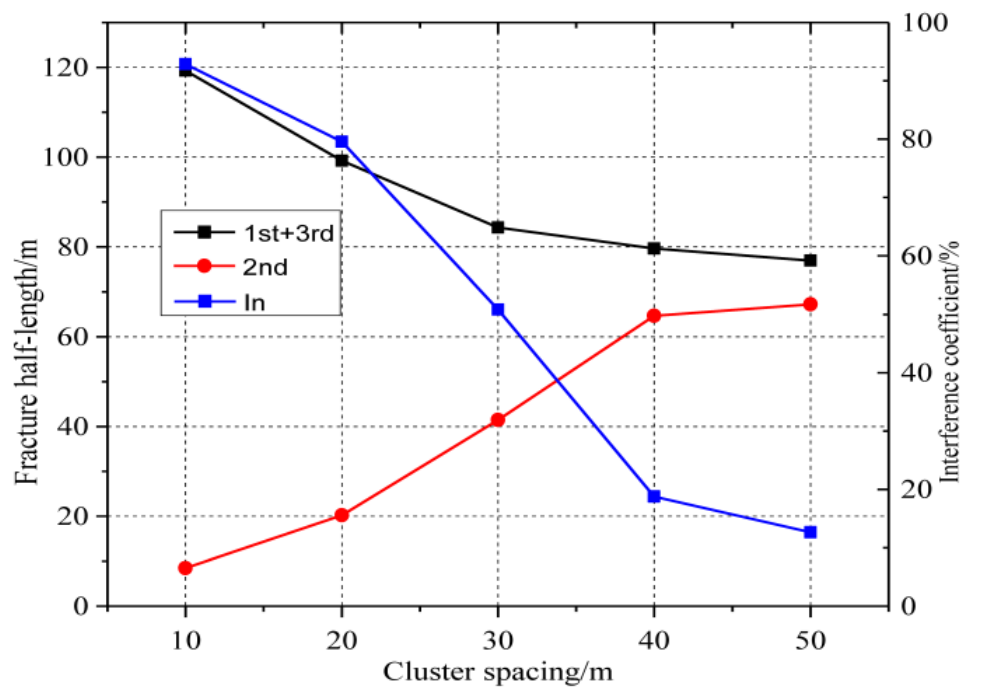

Figure 11: Fracture half-length of all fractures within the single fracturing section when the cluster spacing is different.

When the cluster spacing is only $10 \mathrm{~m}$, the middle fracture (the $2^{\text {nd }}$ fracture) will be strongly affected by the stress interference due to the adjacent fractures, which finally greatly hinders its full propagation. In the end, the half-length of the middle fracture is only $7 \%$ of that of the fractures on both sides within the fracturing section, and the interference coefficient even reaches $92 \%$. With the gradual increase of cluster spacing, the stress interference among the hydraulically induced fractures has been gradually weakened, and the inhibition effect of stress interference on the propagation of middle fracture in the fracturing process has shown the same tendency. When the cluster spacing reaches $40 \mathrm{~m}$, halflength of the middle fracture (the $2^{\text {nd }}$ fracture) is basically equal to that of the two fractures on both sides within the fracturing section. All these results indicate that when the cluster spacing is designed to be $40 \mathrm{~m}$, the stimulation result may be best. Under this condition, the length of each fracturing section is $120 \mathrm{~m}$, so the total number of fracturing section is 10 segments, which are in accordance with the practical fracturing design.

During the actual construction of hydraulic fracturing in the field, the total volume of injected fracturing fluid was 10113 $\mathrm{m}^{3}$, and the volume of the solid proppant used was $35 \mathrm{~m}^{3}$. Earth potential monitoring technology can realize the real-time monitoring of the fracturing construction results. The monitoring results show that the fracturing construction results in the complicated hydraulic fractures and thus effectively stimulate the shale reservoirs. After fracturing, the production test was carried out using a $14 \mathrm{~mm}$-sized production nozzle. The gas production rate obtained by production test was 185000 $\mathrm{m}^{3} /$ day, which showed a significant increase in gas production compared with the adjacent production wells in the same area. 


\section{CONCLUSIONS}

$\mathrm{I}$ $\mathrm{n}$ this paper, a two-dimensional seepage-stress-damage coupled multiple fractures numerical model is developed by using the ABAQUS FEM software. On this basis, the influences of factors, such as the cluster spacing, the elastic modulus and the injection rate of the fracturing fluid, on the fracture propagation morphology have been studied. The results show that:

(1) The cluster spacing is the most important factor that affects the stress interference among all these fractures within the single fracturing section. Exactly, it can be regarded as the most important influential factor. When the cluster spacing is small, the stress interference is obvious, and the propagation of the middle fractures will be severely inhibited. However, with the increase of the cluster spacing, the stress interference among all these fractures within the single fracturing section decrease, so the morphology of all these fractures become uniform and similar.

(2) The elastic modulus of the reservoir hardly affects the stress interference among all these fractures, but it can affect the final morphology of all fractures. With the gradual increase of the elastic modulus, the half-length of each fracture in the single fracturing section increases significantly, while the width of all these fractures obviously decrease, which can greatly increase the possibility of sand plug. Therefore, it is suggested that large cluster spacing should be designed when multicluster staged fracturing is carried out in a reservoir with high elastic modulus, so the difficulty of adding sand due to the thin fracture width can be prevented.

(3) Injection rate of fracturing fluid is also an important factor affecting the crack propagation. With the increase in the injection rate of the fracturing fluid, both the half-length and width of each fracture within the single fracturing section will gradually increase. Therefore, by increasing the injection rate of the fracturing fluid, it is possible to increase both the width and the half-length of fracturing fractures, so more volume of the reservoir can be stimulated.

(4) Simulation results show that the increase in the viscosity of the fracturing fluid results in an increase in the width of all fractures, but it hinders the propagation of all fractures within the single fracturing section. Therefore, increasing the viscosity of the fracturing fluid indefinitely is not conducive to increasing the stimulated reservoir volume, it is recommended to design a suitable viscosity of the fracturing fluid in the actual construction.

\section{REFERENCES}

[1] Ben, Y., Miao, Q. and Wang, Y. (2012). Effect of Natural Fractures on Hydraulic Fracturing, ISRM Regional Symposium-7th Asian Rock Mechanics Symposium, Seoul, Korea,.

[2] Cheng, Z. R., Bunger, A. P. and Zhang, X., (2009). Cohesive zone finite element-based modeling of hydraulic fractures, Acta Mechanica Solida Sinica, 22(5), pp. 443-452.

[3] Vengosh, A., Jackson, R. B. and Warner, N. (2014). A critical review of the risks to water resources from unconventional shale gas development and hydraulic fracturing in the united states, Environmental Science \& Technology, 48(15), pp.8334-8348.

[4] (2016). Future U.S. tight oil and shale gas production depends on resources, technology, markets. https://www.eia.go v/todayinenergy/detail.php?id=27612.

[5] Saldungaray, P. M., Palisch, T. and Shelley, R. (2013). Hydraulic Fracturing Critical Design Parameters in Unconventional Reservoirs, SPE Unconventional Gas Conference and Exhibition, Muscat, Oman.

[6] Rahm, D. (2011). Regulating hydraulic fracturing in shale gas plays: The case of Texas, Energy Policy, 39(5), pp. 29742981.

[7] Gregory, K. B., Vidic, R. D. and Dzombak, D. A. (2011). Water Management Challenges Associated with the Production of Shale Gas by Hydraulic Fracturing, Elements, 7(3), pp. 181-186.

[8] Schnoor, J. L. (2012). Shale gas and hydrofracturing, Environmental Science \& Technology, 46(9).

[9] (2011). Review of Emerging Resources: U.S. Shale Gas and Shale Oil Plays. https://www.eia.gov/analysis/studies/us shalegas/.

[10] Drilling Productivity Report (2014). Washington, DC: United States Energy Information Administration, 10.

[11] Tang, Y., Zhang, J. C. and Zhang, Q., (2010). An analysis of hydraulic fracturing technology in shale gas wells and its application, Natural Gas Industry, 30(10), pp. 33-38.

[12] (2016). Hydraulic fracturing accounts for about half of current U.S. crude oil production. https://www.eia.gov/todayi nenergy $/$ detail.php?id $=25372$. 
[13] Carpenter, C. (2014). Design Optimization of Horizontal Wells With Multiple Hydraulic Fractures, Journal of Petroleum Technology, 66(11), pp. 118-123.

[14] Zhang, G. M., Liu, H. and Zhang, J., (2010). Three-dimensional finite element simulation and parametric study for horizontal well hydraulic fracture, Journal of Petroleum Science and Engineering, 72(3-4), pp. 310-317.

[15] Pan, L. H., Cheng, L. J. and Zhang, Y. (2015). Numerical simulation of fracturing pressure in multiple clusters staged hydraulic fracture of shale horizontal well, Rock and Soil Mechanics, 36(12), pp.3639-3648.

[16] Lo, L. W. (2014). Interaction of growing cracks in hydraulic fracturing, Master thesis, The University of Texas at Arlington.

[17] Peirce, A. (2015). Interference Fracturing: Nonuniform Distributions of Perforation Clusters That Promote Simultaneous Growth of Multiple Hydraulic Fractures, SPE Journal, 20(2), pp. 384-395. 